\title{
Are the psychophysical laws fine-tuned?
}

\section{Dan Cavedon-Taylor ${ }^{1}$}

Received: 7 November 2019 / Accepted: 15 November 2020 / Published online: 24 November 2020

(c) The Author(s) 2020

\begin{abstract}
Neil Sinhababu (Am Philos Q 54(1):89-98, 2017) has recently argued against the fine-tuning argument for God. They claim that the question of the universe's finetuning ought not be 'why is the universe so hospitable to life?' but rather 'why is the universe so hospitable to morally valuable minds?' and that, moreover, the universe isn't so hospitable. For it is metaphysically possible that psychophysical laws be substantially more permissive than they in fact are, allowing for the realisation of morally valuable consciousness by exceptionally simple physical states and systems, rather than the complex states of brains. I reply that Sinhababu's argument rests upon unsupported claims and that we have reason to doubt that an omnibenevolent God would make the psychophysical laws more permissive than they in fact are.
\end{abstract}

Keywords Embodiment · Fine-tuning · Psychophysical laws

\section{Introduction}

Physical cosmologists claim that the universe is balanced on a razor's-edge as far as human life is concerned. Our existence would be impossible had not various forces and constants taken the values that they in fact do. In some cases, minute differences in those values would have entailed a universe devoid of any structure, let alone the complexity to support life.

Three examples of such fine-tuning observations are as follows:

\section{Gravity}

Gravity needs fine tuning for stars and planets to form, and for stars to burn stably over billions of years. It is roughly $10^{39}$ times weaker than electromagnetism. Had it been only $10^{33}$ times weaker, stars would be a billion times less massive and would burn a million times faster. (Leslie 1989, p. 5).

Dan Cavedon-Taylor

dan.cavedon-taylor@open.ac.uk

1 The Open University, MK, UK 


\section{Rate of expansion of the early universe}

If the rate of expansion one second after the Big Bang had been smaller by even one part in 100 thousand million million, the universe would have collapsed before it ever reached its present size. (Hawking 1998, p. 126).

\section{Strong nuclear force}

Calculations indicate that if the strong nuclear force, the force that binds protons and neutrons together in an atom, had been stronger or weaker by as little as 5\%, life would be impossible. (Collins 1999, p. 49).

These observations are surprising. The relevant forces and constants could have taken any one of a vast number of values. So why the ones that they in fact did? What explains the life-friendliness of the universe along so many dimensions? In answer, theists hypothesise a fine-tuning agent, i.e. God, who set the dials 'just right', without which the fine-tuning observations would be unacceptably improbable.

Various non-theistic responses have been offered (see Manson 2009): one might challenge the fine-tuning observations; accept them, but challenge their interpretation or need for explanation; or else accept them but advance a nontheistic hypothesis, like appeal to the existence multiple universes, to sufficiently raise their probability while leaving God out of the picture.

Neil Sinhababu (2017) offers a novel and especially trenchant non-theistic response to the fine-tuning argument. They argue, in effect, that the issue has been wrongly framed as a matter of the fine-tuning of the physical laws and constants. Framed correctly, as a matter of the fine-tuning of the psychophysical laws, Sinhababu argues that God's existence is a non-sequitur insofar as the psychophysical laws are not fine-tuned. I shall attempt to show that Sinhababu's response rests upon unsupported claims and that we have reason to doubt that an omnibenevolent God would make the psychophysical laws more permissive than they in fact are.

\section{Sinhababu's argument}

Sinhababu's response to the fine-tuning argument may be reconstructed as proceeding in three stages.

\section{First stage: reframing the central question}

First, Sinhababu argues that the question of fine-tuning, from the theist's point of view, ought not be 'why is the universe so hospitable to life?' but rather 'why is the universe so hospitable to morally valuable minds?' As he puts it: 
While the intelligent beings we've met have many other properties, such as being carbon-based, cellular, complex, and somewhat squishy, the moral insignificance of these properties renders them unimportant to the argument (p. 424).

The thought is this: what is promoted by the physical laws and constants is carbon-based life. However, what God presumably cares about is something else: morally valuable minds, minds that, e.g., are capable of love, creativity, forgiveness, etc. The question of fine-tuning, from the theist's point of view, ought to be whether the universe is fine-tuned for these specific features. So fine-tuning ought not to be addressed in terms of physical laws and constants, but psychophysical laws, where these are laws concerning what kinds of physical states and systems can instantiate which kinds of mental states. In actuality, psychophysical laws permit the realization of morally valuable consciousness only by relatively complex physical states: those instantiated by certain subset of sufficiently complex and developed brains.

\section{Second stage: the universe is not particularly hospitable to morally valuable minds}

Granted, the universe is somewhat hospitable to morally valuable minds. After all, here we are. Moreover, as Sinhababu points out, the world might conceivably have been less hospitable to minds than it in fact is. Proof: this is not a zombie world, lacking in phenomenal consciousness (p. 426).

Still, the psychophysical laws could have been significantly more mind-friendly. As noted: in actuality, mental states require for their realization physical states that are relatively complex, i.e., those instantiated by certain brains. Crucially, Sinhababu argues that this didn't necessarily have to be the case; it is a metaphysical possibility that morally valuable minds be realized by such simple physical states as those instantiated by mere electrons. Each individual electron might have been an intelligent, conscious being, capable of, e.g., love, creativity, forgiveness, etc. Clearly, such an e-world (as I will call it) is not the actual world. But that is precisely Sinhababu's point: insofar as the e-world is not the actual world, while still being a metaphysically possible one, psychophysical laws might have been a great deal "more permissive" for morally valuable minds than they in fact are. (p. 425).

And so, while the universe might be fine-tuned for carbon-based life, the possibility, yet non-actuality, of the e-world shows that it is not fine-tuned for morally valuable consciousness (granted, it is not entirely un-tuned).

\section{Third stage: theists must affirm the metaphysical possibility of the e-world, on pain of inconsistence}

The obvious reply for the theist to give is to deny the metaphysical possibility of the e-world. Indeed, a point like this is made by Robin Collins, in a paper that anticipates the line of argument developed by Sinhababu: 
Contrary to what one might see on Star Trek, an intelligent life form cannot be composed merely of hydrogen gas: there is simply not enough stable complexity. (1999, p. 56; see also Swinburne 2003, pp. 120-121).

Thus, Sinhababu would appear stuck with a substantial burden in having to establish the metaphysical possibility of the e-world, where psychophysical laws differ radically from our own. No easy task, if the literature on the metaphysical possibility of zombies, and the psychophysical laws of their world, is anything to go by.

At this point, Sinhababu makes a particularly shrewd dialectical move: rather than getting entangled in a positive defence of the metaphysical possibility of the e-world, e.g., against the suggestion that it is a mere Star Trek fantasy, they turn the tables on the theist. Sinhababu notes that theists are committed to the actuality of at least one mind, i.e. God's, that exists without any physical realizer whatsoever. It therefore follows, according to Sinhababu, that the theist must, by their own lights, consider the e-world to be a metaphysical possibility. For the theist's commitment to the existence of a non-physical mind entails commitment to mental states being "completely unconstrained by the physical" (p. 427) which, in turn, entails commitment to the e-world being metaphysically possible. To deny the metaphysical possibility of the e-world would be inconsistent of theists, Sinhababu claims, for they would thereby "violate their own theoretical commitments" (p. 427) regarding the non-physicality of God's mind, and perhaps those of angels too. ${ }^{1}$ In a nutshell:

[Theists are] committed to the existence of a non-physical God with a mind, which leaves them unable to defend restrictions on which physical entities can have minds. (p. 427).

This attempt to turn the tables on the theist is what I shall argue Sinhababu is unsuccessful in achieving. Theists are not required, on pain of incoherence, to affirm the metaphysical possibility of the e-world.

\section{Against Sinhababu's argument}

From the fact that theists believe in at least one mind that is not physically realized, must they admit that minds can have just any physical realizer (making the e-world a metaphysical possibility) and that, therefore, actuality is not fine-tuned for morally valuable consciousness? In other words, is Sinhababu correct to claim that affirming the existence of God makes it "unavailable" to theists to deny the metaphysical possibility of the e-world? (p. 427).

Further reflection suggests not. From the putative fact that some minds, e.g., God's, may exist with no physical realizer it does not follow that it is metaphysically possible that minds can exist with just any physical realizer, when they are so realized. The putative fact that God's mind is not physically realized might be thought to entail only that it is metaphysically possible that God's mind is not physically

\footnotetext{
$\overline{1}$ I owe the point about angels to an anonymous referee.
} 
realized, not that our minds can take just any physical realizer. The greatness of God's mind existing with no physical realizer need not be thought to entail that our lesser minds can take any such realizer: morally valuable mental states like love, creativity, forgiveness, etc. might sometimes be instantiated without a physical realizer but might, on other occasions, only be instantiated in virtue of a physical realizer. (Perhaps in the case of infinite, physically transcendent beings no physical realizer in necessary, while in the case of finite beings like us at least one such realizer is - this is only one option of many.) There is no incoherence in thinking that, when a mind happens to be physically realized, then, as a matter of metaphysical necessity, not just any physical realizer will suffice, while also thinking that there is at least one mind that, in actuality, requires no physical realizer whatsoever.

This puts the ball squarely back in Sinhababu's court. Their attempt to turn the tables on the theist over the matter of whether the e-world is metaphysically possible does not go through. In particular, it is false to say that theists would "violate their own theoretical commitments" (p. 427) were they to insist that the e-world is metaphysically impossible. The shrewd dialectical move fails.

That the e-world is metaphysically impossible is not what I am defending. It suffices to undermine Sinhababu's response to the fine-tuning argument to show that their attempt to sidestep a rigorous defence of the e-world's metaphysical possibility, and simply saddle theists with its affirmation, is not successful. Sinhababu's claim that the e-world is metaphysically possible is therefore without support and their claim that the actual psychophysical laws are not fine-tuned for morally valuable consciousness is not established.

\section{A familiar problem and a familiar reply}

The line of reply I've developed above might be thought to offer cold comfort to the theist. Surely the point of Sinhababu's argument, one might think, is simply that if there is a God, then, as an omnibenevolent being, we should expect them to have engineered the universe such that it is fairly easy for morally valuable consciousness to be instantiated. Insofar as it isn't, then God didn't, and the theist ought to be on the back foot. Thus, the point of Sinhababu's response to the fine-tuning argument can be made without considering a situation as outlandish as the e-world. The e-world is can be construed as simply dramatizing the more general point that God could have promoted morally valuable consciousness in a better way, making such minds more numerous than in actuality, with more permissive psychophysical laws. To make this point, one could focus discussion on worlds in which psychophysical laws differ radically from our own, as in the e-world, but one might not. Focussing discussion on closer worlds, where psychophysical laws are only slightly more permissive, would seem just as dialectically effective, if not more so.

On the one hand, framing Sinhababu's response to the fine-tuning argument in this manner makes the challenge for the theist all the more imposing. For then Sinhababu's challenge is of a kind with the problems of evil/suffering, divine hiddenness and petitionary prayer, etc. namely, why did a supposedly omnibenevolent God engineer the universe the way that they did, e.g., with acts of evil/suffering, without 
unambiguous signs of his existence, with the requirement of supplication for some goods, etc.? Sinhababu's challenge then becomes what we can think of as the problem of psychophysical laws: why did a supposedly omnibenevolent God make it relatively difficult for morally valuable consciousness to be instantiated? Since he is omnibenevolent, he cares about promoting morally valuable consciousness. But then he could have engineered the universe significantly more efficiently than he did, with more permissive psychophysical laws, making morally valuable consciousness more abundant. Developed this way, Sinhababu's argument is not merely a response to the theist who happens to defend the fine-tuning argument, it is an argument against God's existence (at least qua omnibenevolent being).

But while this may seem to make Sinhababu's point all the more substantial, there is a sense in which the sting is simultaneously taken out of the challenge. For a generic reply to the form of the problems listed above is that, despite appearances, God did in fact order the universe in the overall best way for us. More determinate, tailored forms of this reply are then given in the individual cases of evil/suffering, divine hiddenness, petitionary prayer, etc. In the case of evil, there is the free will defence. In the case of divine hiddenness, there is the threat to our moral freedom that might have ensued, were God to unambiguously reveal themselves. In the case of petitionary prayer, there is the worry that we might have been spoiled, were all goods simply provided in advance. In the case of explaining why morally valuable consciousness is not more easily instantiated, the following are but two possible replies that theists might give.

First, take the e-world: theists might grant that this is a metaphysically possible situation which God might have actualised, yet claim that he has overriding moral reason not to do so. For in such a world, the universe is saturated with conscious beings. The claim that this represents an obvious increase in moral value is open to doubt. Yes, if all that matters are considerations of quantity. Perhaps not, if considerations of quality are relevant also. In particular, hydrogen, the most abundant element in the universe, contains only one electron. This means that substantial sectors of the e-world, if actualised, would be populated by isolated conscious beings leading insular lives with very few companions, despite having the exact same capacity for love, creativity, forgiveness, etc. as we have. The wildly permissive psychophysical laws of such a world would thus appear to promote an abundance of lonely and small-minded individuals, with limited perspectives on, and a narrow understanding of, the universe. Theists may reasonably claim that this is not a state of affairs that an omnibenevolent God would wish to actualise.

One might reply that God could of course tinker with the e-world such that matter is more densely packed than in actuality, ensuring that large numbers of electrons aren't at risk of living dreary, unfulfilling lives. At first glance, this reply seems plausible. Dialectically, however, it is problematic. For it would require God's tinkering with some of the physical laws and constants too, and so would be to affirm that these are not fine-tuned in the first place. Were that true, then there would be no need for Sinhbabu's argument, making it redundant.

Second, consider a world where psychophysical laws are only slightly more permissive than in actuality, and where consciousness is realized by the kinds of systems commonly thought to embarrass the mind-body functionalist, e.g., complex 
networks of water pipes (Searle 1980), electrical circuits, and the like-systems that are functional duplicates of us and/or our brains, and which might conceivably have been conscious, but which we doubt are conscious in actuality. There are more morally valuable consciousnesses in existence in this world than there are in ours (call it the f-world). Again, going by quantity alone, the f-world seems to represent an increase in moral value over our own. Yet, when one focusses on quality, there is reason to worry. In such a world, the percentage of conscious unable to communicate or exert bodily agency risks increasing dramatically. For the psychophysical laws in that world encourage the existence of minds suffering from locked-in syndrome, with minds paralysed in water pipes, electrical circuits, etc. rather than human bodies. Again, it is not obvious why an omnibenevolent God should have actualised such a state of affairs. The reply that God would engineer that world such that these agents are not locked-in would again require tinkering with the physical laws and constants, and so would again be to make Sinhababu's argument superfluous. That God should have made the psychophysical laws even slightly more permissive is, again, open to doubt. ${ }^{2}$

\section{Conclusion}

None of this proves that our psychophysical laws occupy a morally/modally finetuned 'sweet spot'. Rather, the point is to force the following dilemma for Sinhababu's line of argument. Either, (1) the metaphysical possibility of the e-world is an unargued assertion, the truth of which Sinhababu wrongly claims the theist must commit to (as argued in section "Against Sinhababu's argument"); or else, (2) it must be shown that it would have been overall morally better for our psychophysical laws to be more permissive, even assuming they could be, when we have some reason to doubt that this is necessarily the case (as argued in section "A familiar problem and a familiar reply"). More to the point, merely showing that morally valuable consciousness could have been more abundant is insufficient to establish that God should have actualised any such situations, for they may be ones in which a significant number of the newly introduced minds are unable to flourish properly (or at least as fully as they can in ours), and it should not simply be assumed that they would. Either way, as novel as Sinhababu's case against the fine-tuning argument is, it is not proved. ${ }^{3}$

\footnotetext{
${ }^{2}$ An anonymous referee claims that theists need not even grant that the e-world (or f-world, or any other world with more permissive psychological laws than those at ours) is metaphysically possible, but that God may not want to actualise it; rather, theists may be content with the fact that we do not have sufficiently overriding reason to think that God would do so. For, given the high degree of fine tuning in our world, as illustrated at the beginning of this paper, the probability of its not being designed is sufficiently miniscule that Sinhababu would need to show it to be tremendously more probable that God would create one of these other worlds over ours.

${ }^{3}$ An anonymous referee also suggests that theists may think that there is value to our being embodied in complex physical systems, rather than mere electrons, insofar as with greater physical complexity comes greater vulnerability to others. The idea that such vulnerability allows certain goods to be realised is central to the free-will theodicy of Richard Swinburne (1999, p. 245) and the connection-building theodicy of Robin Collins (2013, p. 226).
} 
Acknowledgements My thanks to colleagues and students at the Open University for feedback on an earlier version. Thanks also to Sinhababu, Eric Moore and an anonymous referee for comments.

Open Access This article is licensed under a Creative Commons Attribution 4.0 International License, which permits use, sharing, adaptation, distribution and reproduction in any medium or format, as long as you give appropriate credit to the original author(s) and the source, provide a link to the Creative Commons licence, and indicate if changes were made. The images or other third party material in this article are included in the article's Creative Commons licence, unless indicated otherwise in a credit line to the material. If material is not included in the article's Creative Commons licence and your intended use is not permitted by statutory regulation or exceeds the permitted use, you will need to obtain permission directly from the copyright holder. To view a copy of this licence, visit http://creativecommons.org/licen ses/by/4.0/.

\section{References}

Collins, R. (1999). A scientific argument for the existence of god: The fine-tuning design argument. In M. Murray (Ed.), Reason for the hope within. US: Wm. B. Eerdermans.

Collins, R. (2013). The connection-building theodicy. In J. McBrayer \& D. Howard-Snyder (Eds.), The blackwell companion to the problem of evil. US: Wiley-Blackwell.

Hawking, S. (1998). A brief history of time. UK: Bantam.

Leslie, J. (1989). Universes. UK: Routledge.

Manson, N. (2009). The fine-tuning argument. Philosophy Compass, 4(1), 271-286.

Searle, J. (1980). Minds, brains, and programs. Behavioral and Brain Sciences, 3(3), 417-457.

Sinhababu, N. (2017). Divine fine-tuning vs electrons in love. American Philosophical Quarterly, 54(1), 89-98.

Swinburne, R. (1999). Providence and the problem of evil. Oxford: OUP.

Swinburne, R. (2003). The argument to god from fine-tuning reassessed. In Manson (Ed.), God and design. UK: Routledge.

Publisher's Note Springer Nature remains neutral with regard to jurisdictional claims in published maps and institutional affiliations. 